\title{
Sistem Informasi Manajemen Konfeksi Pakaian Di Ady Taylor Berbasis Website
}

\author{
Lailatul Ismi $^{* 1}$, Maulidiansyah ${ }^{2}$, Wahab Sya'roni ${ }^{3}$ \\ 1,2,3 Prodi Informatika Fakultas Teknik Universitas Nurul Jadid \\ Karanganyar Paiton Probolinggo \\ e-mail: ${ }^{1 *}$ lailaismi008@gmail.com, ${ }^{2}$ maulid@unuja.ac.id, ${ }^{3}$ wahab.syaroni@gmail.com
}

\begin{abstract}
Abstrak
Konfeksi Adalah usaha pembuatan pakaian, termasuk kemeja, celana, kemeja, jaket, jas dan bentuk pakaian lainnya. Dari perspektif volume produksi dan perputaran modal produksi, perusahaan ini dapat dibagi menjadi perusahaan besar atau perusahaan kecil. Ady Taylor Convection adalah usaha yang bergerak di bidang industri pakaian atau yang dikenal usaha konfeksi. Ady Taylor Convection dibangun sejak 1992, dan sudah melewati berbagai perubahan, namun seiring peningkatan pelanggan tiap tahunnya banyak perubahan-perubahan yang harus dilakukan. Seperti, persediaan bahan baku yang di butuhkan sesuai pesanan, dan tersediannya contoh jenis pakaian yang akan di buat untuk membantu karyawan dalam menyelesaikan pekerjaannya supaya kebutuhan konsumen terpenuhi secara efisien dan maksimal terutama pada pengolahan bahan bakunya. Sering terjadi kerugian pada setiap pengusaha konfeksi dikarenakan pengolahan bahan yang tidak terkontrol, pengadaan alat-alat yang dibutuhkan tidak tersedia dengan segera, dan tidak tersedia contoh pakaian sesuai pesanan maka dibutuhkan suatu sistem informasi manajemen konfeksi pakaian di Ady Taylor berbasis website. Dalam hal ini peneliti menggunakan metode waterfall dan dari hasil penelitian di peroleh kesimpulan bahwa sistem informasi yang telah dibangun tersebut sangat baik dan layak untuk digunakan serta semua fungsi dapat digunakan. Sistem informasi tersebut dapat merekap laporan dan dapat mengolah data bahan baku dengan baik.
\end{abstract}

Kata kunci: Konfeksi, Waterfall, Website

\begin{abstract}
Convection is a business of making clothes, both clothes in the form of shirts, pants, shirts, jackets, suits, and others. This business can be included in large-scale or small-scale businesses seen from the quantity of production and the turnover of capital used in production. Ady Taylor convection is a business engaged in the clothing industry or what is known as a convection business. Ady Taylor convection has been built since 1992, and has gone through various changes, but as customers increase each year there are many changes that must be made. For example, the inventory of raw materials needed according to order, and the availability of examples of the types of clothing that will be made to assist employees in completing their work so that consumer needs are met efficiently and maximally, especially in the processing of raw materials. There are often losses for every convection entrepreneur due to uncontrolled material processing, the procurement of the tools needed is not available immediately, and there are no available samples of clothing to order, so a website-based clothing management information system is needed at Ady Taylor. In this study using the waterfall method and from the results of the study it was concluded that the information system that has been built is very good and feasible to use and all functions can be used. The information system can recap reports and can process raw material data properly.
\end{abstract}

Keywords: Convection, Waterfall, Website 


\section{PENDAHULUAN}

Konfeksi Konfeksi merupakan usaha pembuatan pakaian, termasuk kemeja, celana, kemeja, jaket, jas dan bentuk pakaian lainnya. Dari perspektif volume produksi dan perputaran modal produksi, perusahaan ini dapat dibagi menjadi perusahaan besar atau perusahaan kecil [1]. Ady Taylor Convection adalah usaha yang bergerak di bidang industri pakaian atau yang dikenal usaha konfeksi. Ady Taylor Convection dibangun sejak 1992, dan sudah melewati berbagai perubahan. Mulai dari perubahan jumlah penyimpanan data pelanggan atau jumlah transaksi yang setiap tahunnya meningkat dari 200 pelanggan perbulan yang hampir rata-rata perpelanggan memesan 2 kodi pakaian atau setara dengan 40 potong pakaian dan pemesanan pakaian menjadi 8000 potong pakaian perbulan, meningkat sampai 250 pelanggan dalam tiap bulan dan produksi mengalami peningkatan sampai 8200 potong pakaian perbulan. dan pertahun penjualan mencapai 3000 pelanggan sehingga dalam pertahun mencapai produksi 120.000 potong.

Namun seiring peningkatan pelanggan tiap tahunnya banyak perubahan-perubahan yang harus dilakukan. Seperti, persediaan bahan baku yang di butuhkan sesuai pesanan, dan tersediannya contoh jenis pakaian yang akan di buat untuk membantu karyawan dalam menyelesaikan pekerjaannya supaya kebutuhan konsumen terpenuhi secara efisien dan maksimal terutama pada pengolahan bahan bakunya. Sering terjadi kerugian pada setiap pengusaha konfeksi dikarenakan pengolahan bahan yang tidak terkontrol, pengadaan alat-alat yang dibutuhkan tidak tersedia dengan segera, dan tidak tersedia contoh pakaian sesuai pesanan. Kemajuan teknologi yang semakin meningkat dengan pelayanan-pelayanan pengusaha yang semakin istimewa dengan memanjakan pelanggan dalam penyajian pesanan sehingga membuat banyak orang ingin berlangganan. tapi sedikit pengusaha yang memperhatikan proses pengolahannya, padahal usaha akan berjalan lancar apabila pengolahannya berjalan dengan benar. Sistem informasi manajemen adalah suatu sistem yang merupakan rangkaian bagian/komponen terorganisir yang bekerja sama atau bergerak untuk menghasilkan informasi bagi manajemen perusahaan. [2].

Penelitian yang dilakukan oleh (Wahdah et al., 2019) dengan judul "Pengembangan Aplikasi Manajemen Perencanaan Bahan Baku Dan Pemesanan Pada Konveksi Sablon Malang" latar belakang pada penelitian ini yaitu Sablon Malang adalah usaha sablon konveksi yang tetap bekerja 24 jam, dan sablon Malang memisahkan lokasi produksi antara satu dengan yang lain. Berdasarkan hasil pengujian yang dilakukan dengan teknik white box testing yang diujikan pada unit test diperoleh kompleksitas 3 sampai 8 lingkaran dan menghasilkan angka signifikan 100\%. Demikian pula, teknologi pengujian kotak hitam melakukan pengujian verifikasi pada semua persyaratan fungsional, dan hasilnya $100 \%$ valid. Hal ini menunjukkan bahwa sistem dapat dioperasikan untuk pengelolaan bahan baku dan data pemesanan untuk sablon kota Malang. Dalam tes non-fungsional, ditemukan bahwa setiap invasi $100 \%$ efektif [3].

Penelitian kedua dilakukan oleh (Sanwasih \& Sodikin, 2017) dengan judul "Rancang Bangun Aplikasi Pengolahan Bahan Baku Konveksi Berbasis Web Studi Kasus Di PT. AlFahmi Collection", Bisnis konveksi merupakan usaha yang sangat umum di Indonesia, hampir di seluruh wilayah. Popularitas usaha konveksi terutama dipengaruhi oleh dua hal. Pertama, yang diproduksi oleh industri konveksi yaitu sandang termasuk kebutuhan pokok manusia, sehingga pasar usaha konveksi akan terus ada. Kesimpulan dari penelitian ini yaitu Aplikasi pengolahan bahan baku konveksi dapat memberikan kemudahan dalam proses pengolahan bahan baku sesuai pesanan. Dari penerimaan pesanan, pengadaan bahan baku dan bahan pendukung lainnya seperti resleting, benang, pelastik, dan tambahan lainnya yang di butuhkan, 
dan di lengkapi contoh pakaian pesanan, untuk memudahkan karyawan dalam pembuatan atau pengolahannya [4].

Penelitian ketiga dilakukan oleh (Farhan, 2020) dengan judul "Perancangan Sistem Inventori Dan Penjualan Pakaian Di Konveksi Aulia Collection" Sistem persediaan dan penjualan adalah suatu hal yang penting bagi perusahaan, dan perlu di management secara efektif dan efisien. Dalam penelitian ini memiliki tujuan yaitu untuk melihat sistem yang beroperasi di Aulia untuk mengumpulkan konveksi. Permintaan pasar untuk bisnis ini sangat besar. Oleh karena itu, usaha dapat diwujudkan melalui rencana penambahan modal usaha, penambahan tenaga kerja, total produksi, peningkatan jumlah penjualan, dan penyempurnaan strategi pemasaran. Beberapa kesimpulan yang dicapai peneliti adalah. Sistem penjualan Aulia Collection Convection yang terkomputerisasi yang diusulkan oleh peneliti merupakan jalan pintas untuk memecahkan masalah untuk membantu mengatasi masalah pada sistem yang lama. Sistem penjualan yang ada saat ini menangani semua permasalahan di Konveksi Aulia Collection, karena sistem yang digunakan masih manual [5].

Dari ketiga hasil penelitian diatas, perbedaan ketiga penelitian tersebut dengan yang saat ini dikerjakan adalah objek penelitian yang digunakan berbeda. Objek peneliti pertama yaitu Konveksi Sablon Malang dan penelitian kedua yaitu PT. Al-Fahmi Collection serta peneliti ketiga menggunakan berada di Konveksi Aulia Collection, Sedangkan penelitian yang sedang dibangun ini difokuskan pada aplikasi pengelolaan bahan baku pada konvesi berbasis website serta berdasarkan uraian masalah diatas, oleh karena itu ady taylor membutuhkan suatu sistem informasi manajemen konfeksi pakaian di Ady Taylor berbasis website sehingga bisa menjawab permasalah yang saat ini dialami oleh Ady Taylor, sehingga pengelolaan bahan baku pada Ady Taylor bisa tertata dan terdata dengan baik dan benar.

\section{METODE PENELITIAN}

Metode penelitian kualitatif merupakan salah satu model penelitian yang memanfaatkan peneliti sebagai peran utama, dipadukan dengan teknologi pengambilan data. Analisis data bersifat induktif serta hasil metode kualitatif lebih memfokuskan pada makna, daripada generalisasi [6].

Model air terjun (waterfall) biasanya disebut juga model urutan linier atau siklus hidup klasik (classic life cycle). Model waterfall menggunakan urutan linear dalam perangkat lunak sekuensial mulai dari analisa kebutuhan, desain sistem, implementasi kode, pengujian, serta tahap dukungan [7]. Di bawah ini adalah gambaran fase atau tahapan pada model waterfall sebagai berikut: 


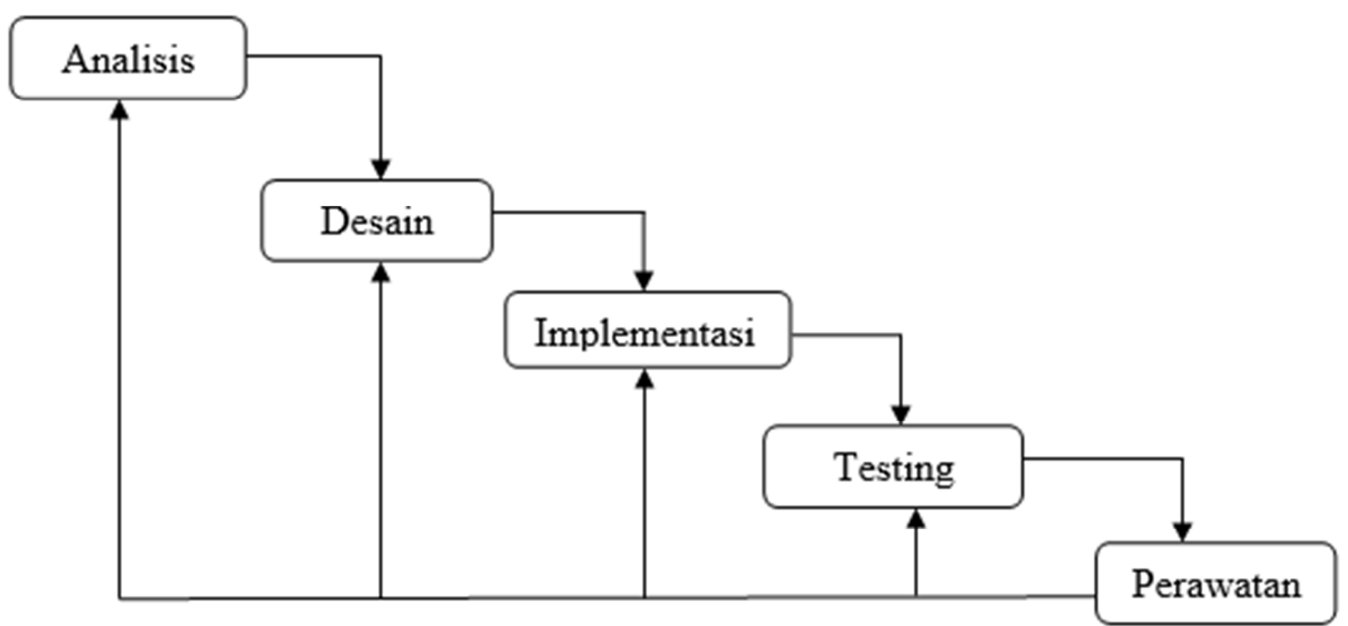

Gambar 1. Model Waterfall [7]

\subsection{Analisa Kebutuhan}

Analisis kebutuhan dapat didefinisikan sebagai kemampuan, kondisi atau Standar yang harus dipenuhi oleh aplikasi untuk memenuhi harapan pengguna. Analisis kebutuhan aplikasi dibedakan menjadi dua bagian yaitu fungsional dan non fungsional. Analisa dilakukan dengan cara wawancar dan observasi tujuannya untuk mendapatkan hasil kebutuhan fungsional dan non fungsional dari system.

\subsection{Desain Sistem}

Berdasarkan kebutuhan fungsional serta non fungsional yang peneliti dapatkan pada tahap analisa, maka akan dilakukan perancangan desain sistem pada tahap ini. Untuk itu diperlukan usaha dalam merancang sistem komputerisasi yang akan mampu memaksimalkan aplikasi yang akan dijalankan agar dapat mencapai hasil yang maksimal. Salah satu desain dalam perancangan sistem, perancangan awal yaitu system Flowchart.

\subsection{Implementasi}

Setelah melakukan analisa kebutuhan sistem dan desain sistm, selanjutnya akan mengimplementasikan hasil dari analisan dan desain sistem yang diharapkan bisa membantu dalam proses pengolaan bahan baku dengan baik dan benar, sehingga omzet yang dihasilkan bisa meningkat. Pada penelitian ini peneliti menggunakan program Web. Sedangkan untuk basisdatanya penliti akan menggunakan MySQL.

\subsection{Pengujian}

Pengujian Sistem Informasi Manajemen Konfeksi Pakaian di Ady Taylor Berbasis Website. Dalam pengujian ini, dilakukan agar peneliti mengaetahui bahwa program yang telah dibangun sudah sesuai atau tidak. Dalam hal ini pengujian program akan dilakukan dengan melakukan dua pengujian yaitu internal (blackbox testing) dan eksternal (user).

a. Internal (Blackbox Testing)

Melakukan pengujian blackbox untuk memastikan bahwa setiap unit dan proses beroperasi seperti yang diharapkan. BlackBox Testing adalah salah satu pengujian program yang difokuskan pada fungsi dari program yang telah dibuat. Blackbox Testing bekerja dengan melihat apakah fungsi yang ada pada sistem bekerja dengan baik atau tidak [8]. 
b. Eksternal (User)

Pengujian eksternal user yang dimaksud adalah untuk mengetahui persentase respon user terhadap Sistem Informasi Manajemen Konfeksi Pakaian di Ady Taylor Berbasis Website. Dalam proses pengujian eksternal, Peneliti akan membagikan sebuah angket dan validasi untuk memperoleh feedback terhadap penggunaan Sistem Informasi Manajemen Konfeksi Pakaian di Ady Taylor Berbasis Website. Skala Likert merupakan skala yang telah banyak dipakai dalam pengujian eksternal seperti angket, dan menjadi skala yang paling umum digunakan dalam penelitian berupa angket atau kuesioner [9].

\subsection{Perawatan}

Proses terakhir yaitu melakukan pemeliharaan terhadap program yang sudah dibuat yaitu Sistem Informasi Manajemen Konfeksi Pakaian di Ady Taylor Berbasis Website. Tahapan pemeliharaan ini dilakukan oleh admin dengan mengupdate data untuk meningkatkan kualitas sistem agar jauh lebih baik. Pada tahap ini sistem akan diperbaiki jika terdapat error yang tidak ditemukan pada tahapan sebelumnya

\section{HASIL DAN PEMBAHASAN}

\subsection{Hasil Pengumpulan Data}

Data yang diperoleh dengan proses wawancara dan observasi di konfeksi ady taylor yang beridi sejak 1992. Proses pengumpulan data yang berupa observasi dan wawancara ini dilakukan agar mengetahui letak masalah dan kendala yang terdapat pada konfeksi ady taylor. Wawancara telah dilakukan dengan pihak pengelola konfeksi ady taylor dan hasilnya bahwa selama ini pihak konfeksi ady taylor menghadapi beberapa kendala dalam proses administrasi, sehingga dirasa aplikasi tersebut perlu dikembangkan menjadi aplikasi berbasis website yang mampu memberikan kemudahan dalam proses administrasi. Selain melakukan wawancara, juga dilakukan observasi terhadap proses penerimaan pesanan di konfeksi ady taylor, pencatatan bahan baku dan juga pembuatan laporan.

\subsection{Desain Sistem}

Dalam tahap desain sistem peneliti mengimplementasikan hasil dari analisa kebutuhan menjadi suatu desain sistem agar dapat terapkan pada tahap selanjutnya. Tahapan-tahapan desain ini meliput alur sistem (Flowchart) dimana terdapat flowchart sistem lama yang saat ini sedang digunakan dan flowchart sistem baru yang peneliti usulkan.

\section{a. Flowchart Sistem Lama}

Sistem flowchart lama menerangkan alur kerja dari Sistem Informasi Manajemen Laundry dalam pendataan pakaian masuk dan keluar, mengolah data pelanggan dan pembuatan laporan. Berikut adalah gambaran flowchart sistem lama yang saat ini sedang digunakan seperti gambar 2: 


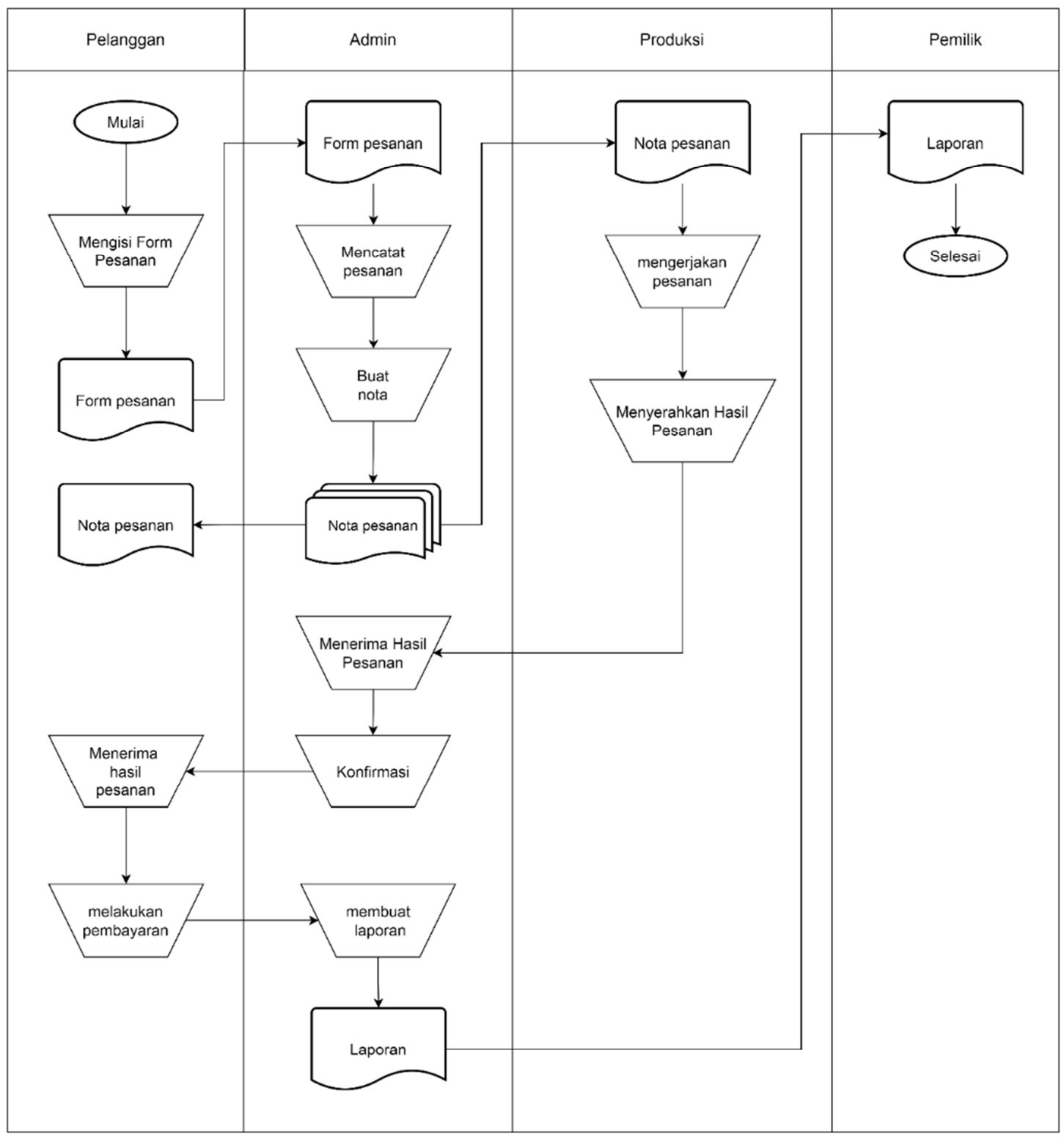

Gambar 2. Flowchart Sistem Lama 
b. Flowchart Sistem Baru

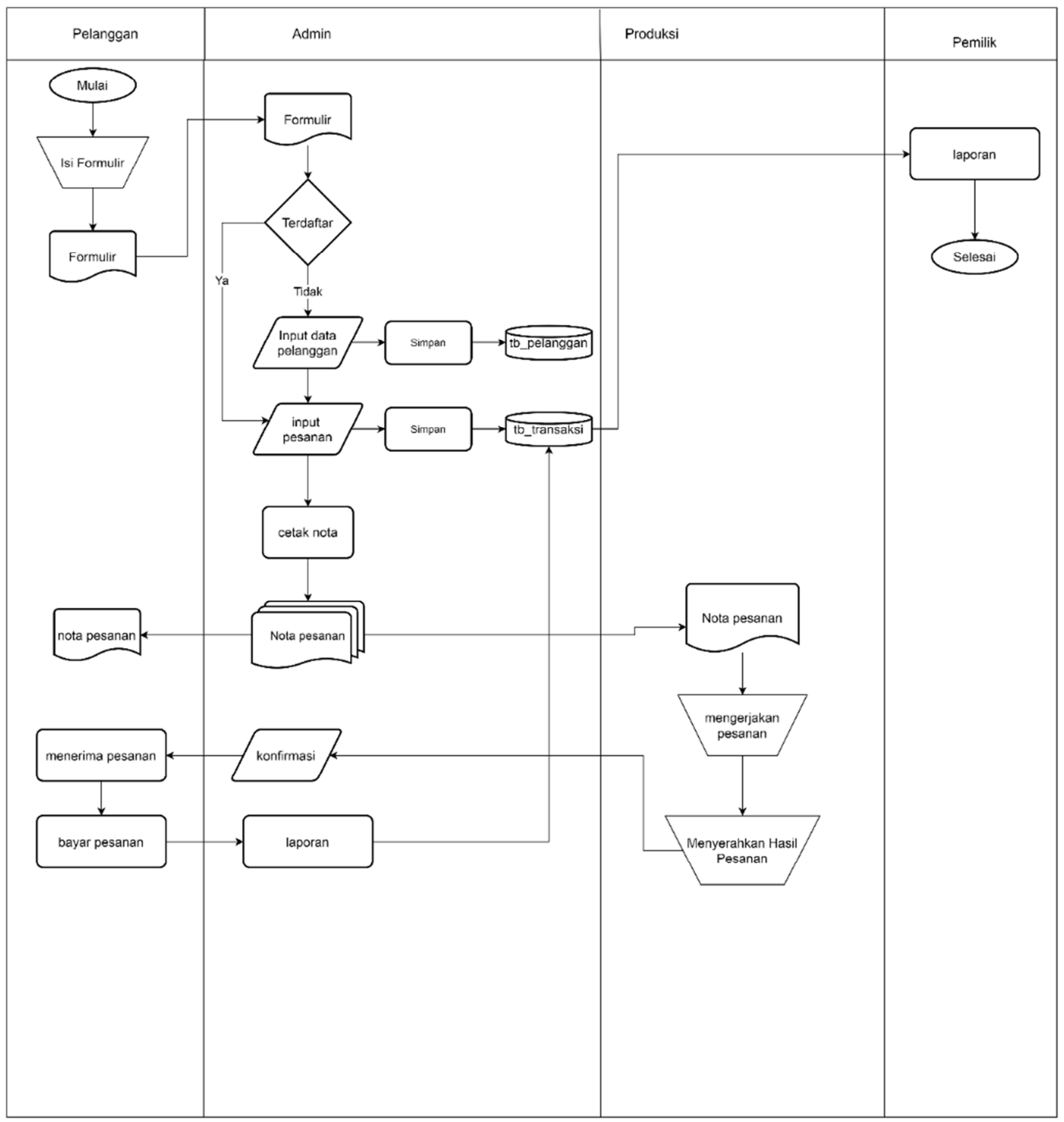

Gambar 3. Flowchart Baru 


\subsection{Implementasi}

a. Screenshot Login

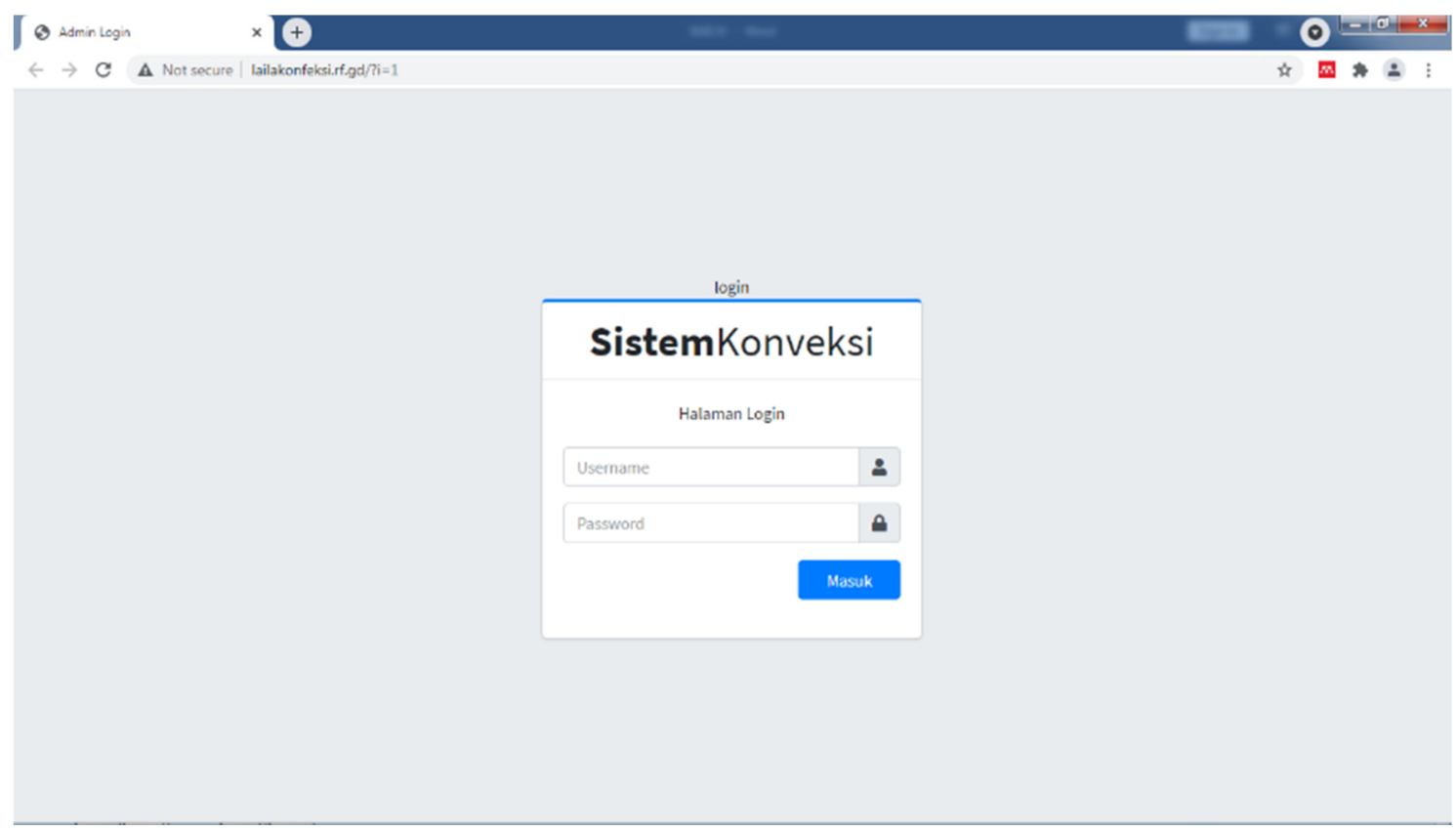

Gambar 4. Screenshot Login

b. Form Dashboard

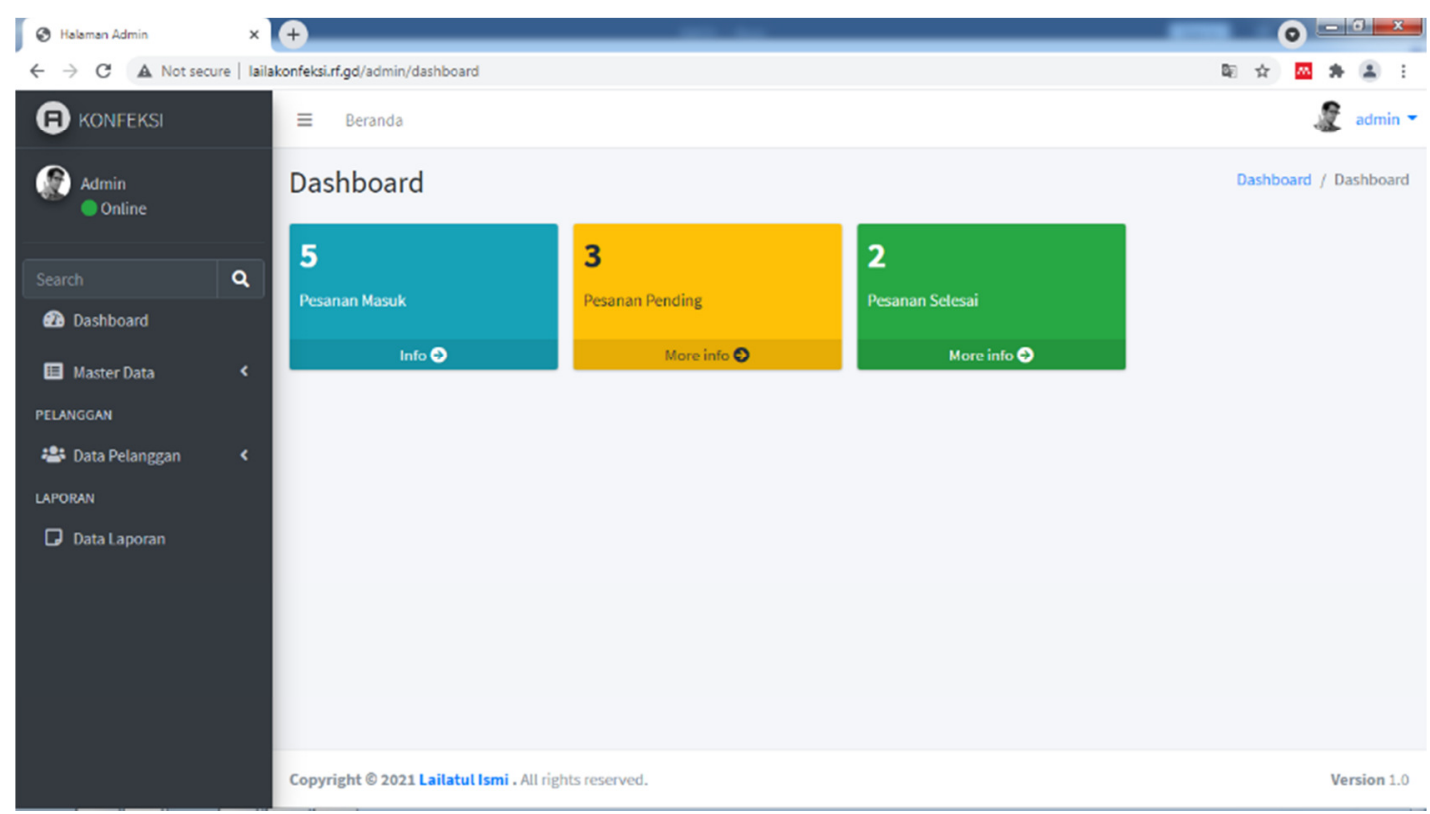

Gambar 5. Screenshot Dashboard 
c. Form User

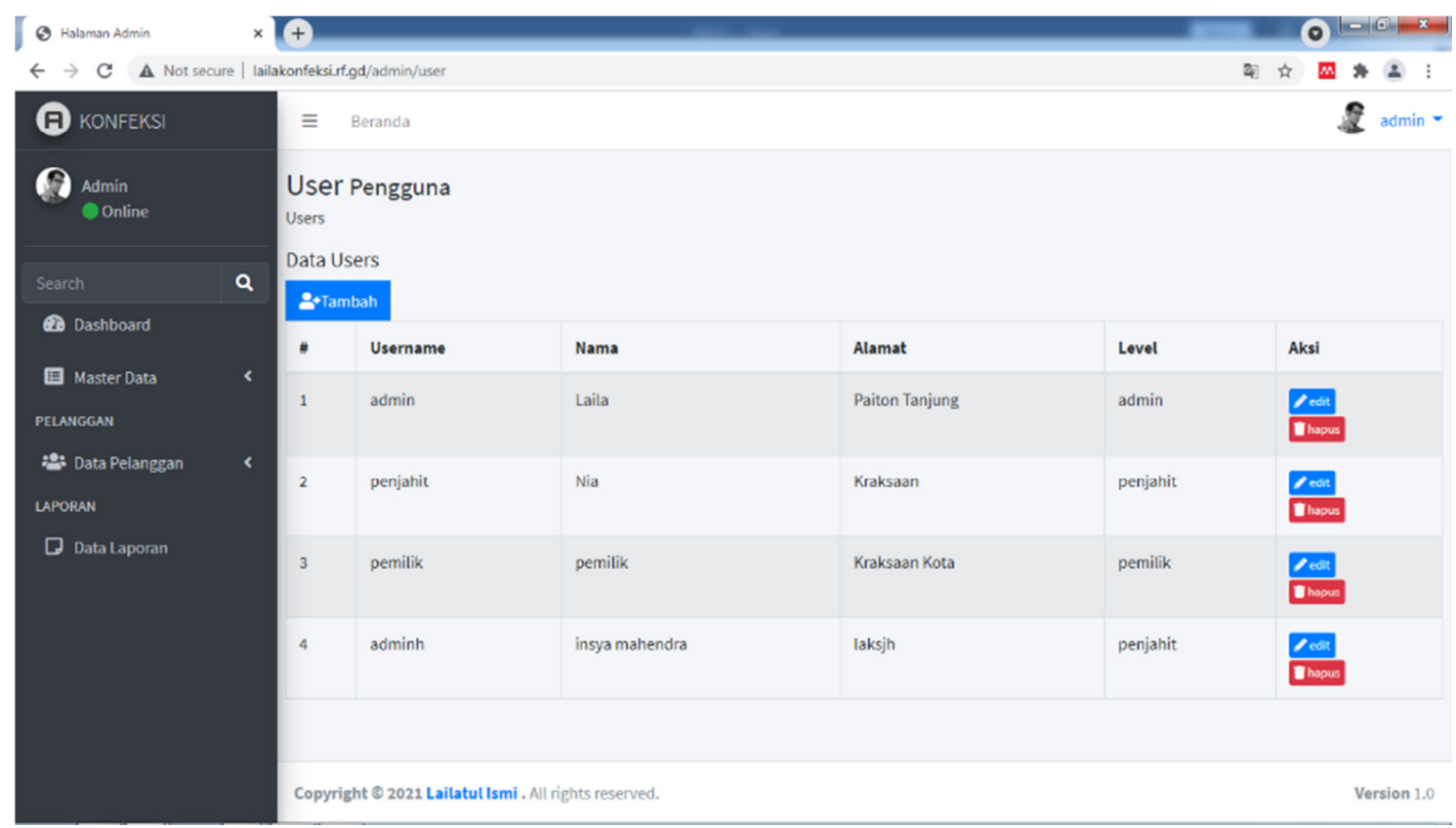

Gambar 6. Screenshot Form User

d. Form Data Bahan

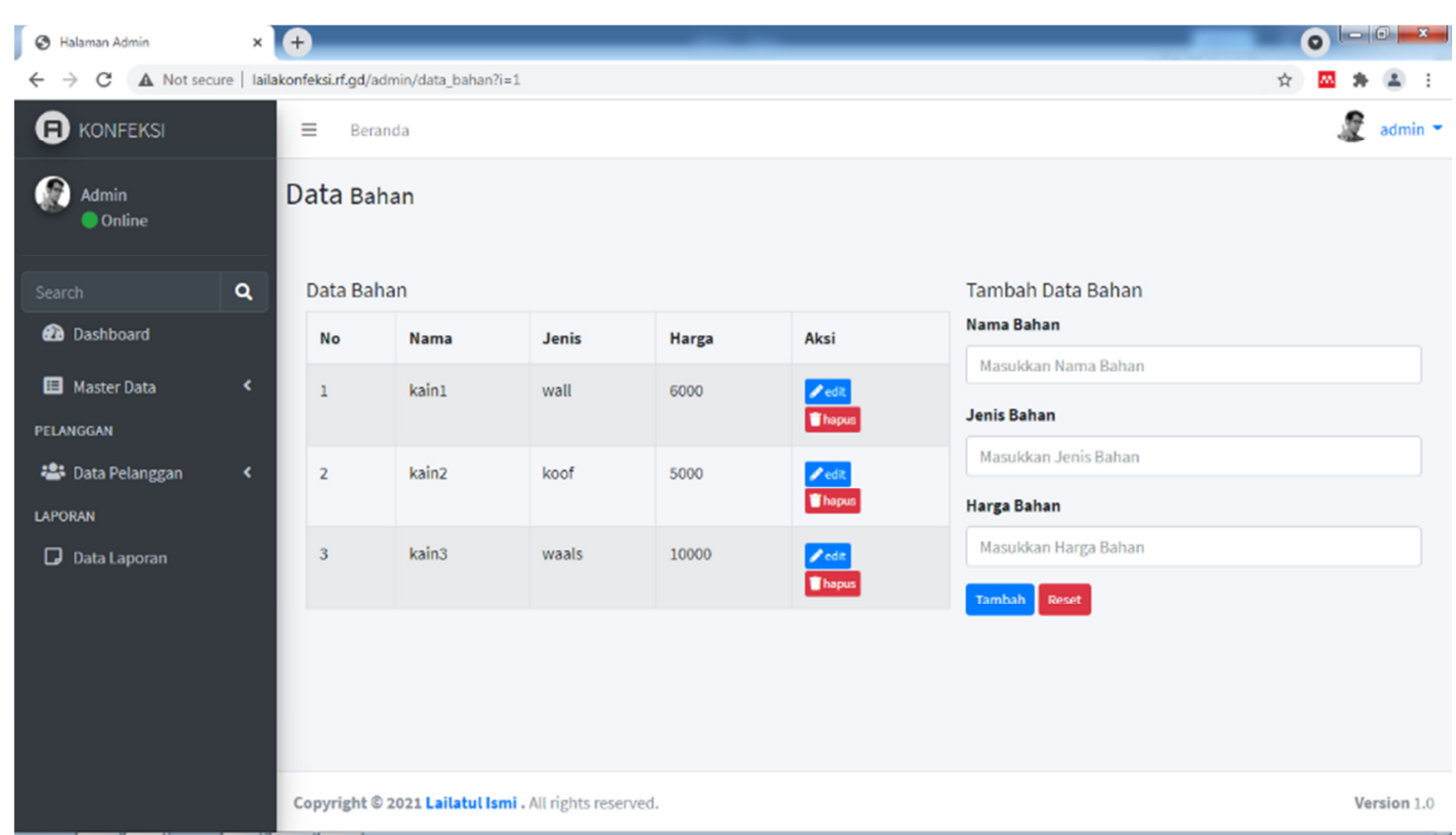

Gambar 7. Screenshot Form Data Bahan 
e. Form Tambah Data Pesanan

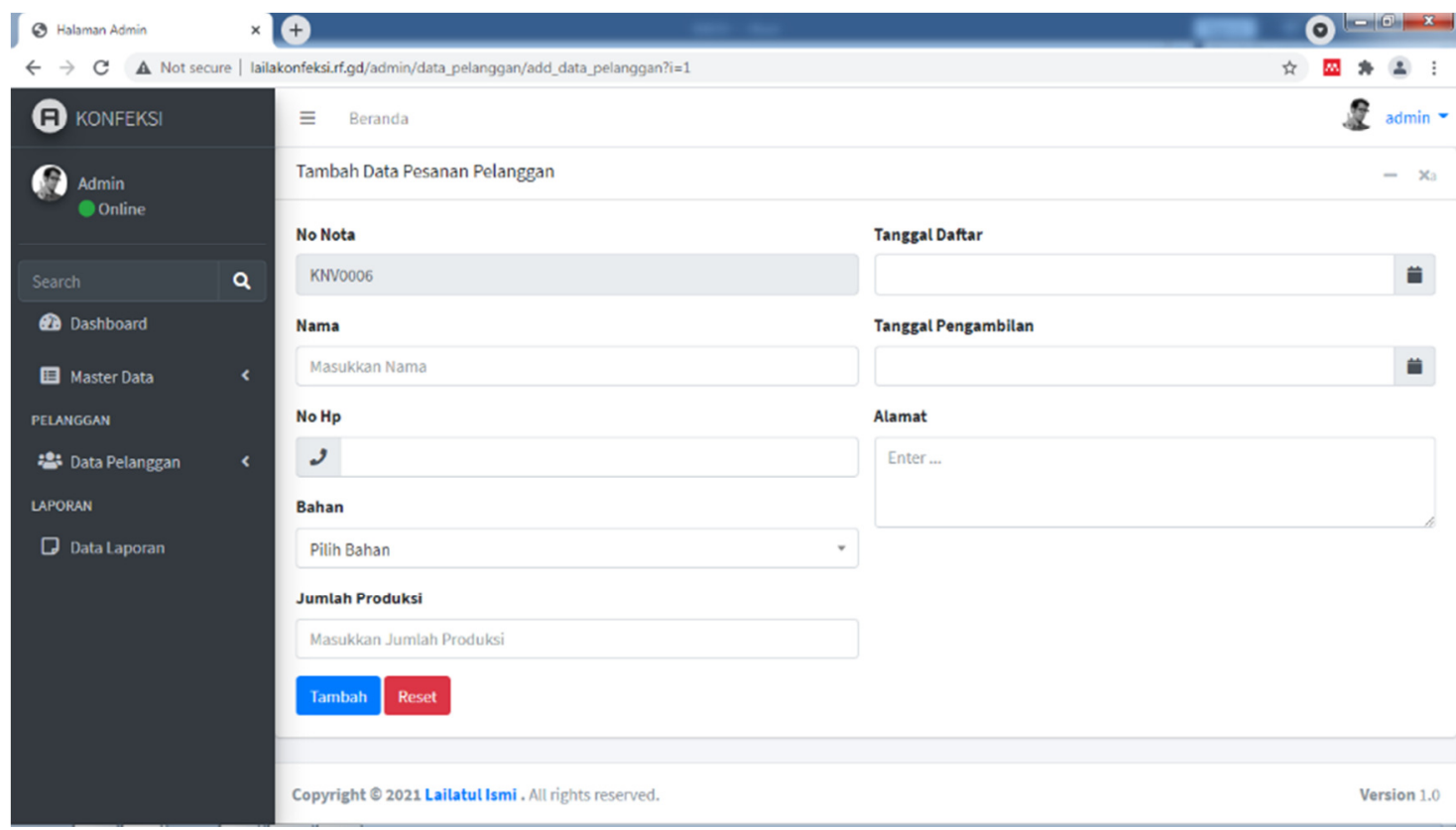

Gambar 8. Screenshot Form Tambah Data Pesanan

\section{f. Form Data Pesanan}

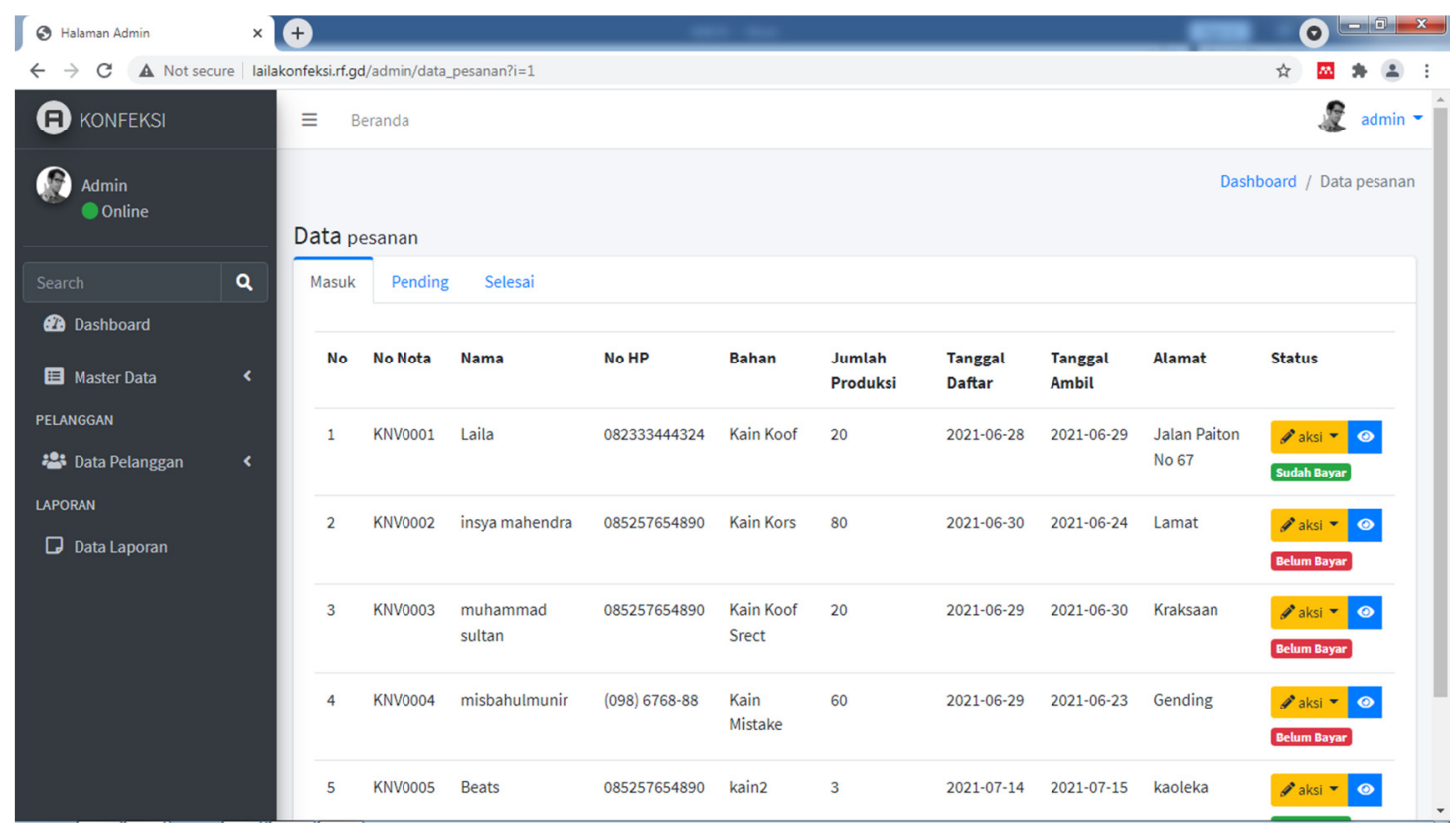

Gambar 9. Screenshot Form Data Pesanan 


\subsection{Pengujian}

Setelah tahap impementasi selesai dan aplikasi yang dibuat telah memenuhi harapan dari peneliti maka tahap selanjutnya adalah analisa data instrumen validasi ahli menggunakan skala Likert. Skala Likert yaitu skala yang telah banyak dipakai dalam pengujian eksternal seperti angket, dan salah satu skala paling umum dipakai dalam penelitian berupa angket atau kuesioner [10].

\section{a. Kuesioner}

Pada pengujian eksternal ini peneliti menguji dengan cara uji langsung program kepada pengguna. Peneliti menggunakan hasil kuisioner dengan perhitungan skala likert untuk mengetahui opini pengguna, sikap, atau feedback pengguna aplikasi dalam angket dan umum digunakan untuk suatu penelitian yang berupa survey atau kuesioner. Pada tahap pengujian Sistem Informasi Manajemen Konfeksi Pakaian Di Ady Taylor Berbasis Website dilakukan pengujian kepada 5 petugas (sebagai pengelola konfeksi).

Tabel 1. Kuesioner

\begin{tabular}{|c|c|c|c|c|c|}
\hline \multirow{2}{*}{ No. } & \multirow{2}{*}{ Pertanyaan } & \multicolumn{4}{|c|}{ Kesimpulan } \\
\hline & & SS & $\mathrm{S}$ & TS & STS \\
\hline 1 & $\begin{array}{l}\text { Apakah menurut anda aplikasi sistem } \\
\text { informasi manajemen ini sudah layak } \\
\text { digunakan di konfeksi ady taylor? }\end{array}$ & 3 & 2 & & \\
\hline 2 & $\begin{array}{l}\text { Apakah dengan sistem informasi } \\
\text { manajemen ini dapat mempermudah } \\
\text { dalam pengolahan data? }\end{array}$ & 3 & 1 & 1 & \\
\hline 3 & $\begin{array}{l}\text { Apakah anda menyukai sistem informasi } \\
\text { manajamen ini? }\end{array}$ & 2 & 2 & 1 & \\
\hline 4 & $\begin{array}{l}\text { Apakah sistem informsi ini memiliki } \\
\text { kecepatan transfer data yang optimal? }\end{array}$ & 4 & 1 & & \\
\hline 5 & $\begin{array}{l}\text { Apakah sistem informasi ini sederhana dan } \\
\text { mudah digunakan bagi petugas dalam } \\
\text { mengoperasikan }\end{array}$ & 3 & 1 & 1 & \\
\hline
\end{tabular}

Total skor yang didapat dari semua pengguna :

Total skor Sangat Setuju (SS) $\quad=15 \times 4=60$

Total skor Setuju (S) $\quad=7 \times 3=21$

Total skor Tidak Setuju (TS) $\quad=3 \times 2=6$

Total skor Sangat Tidak Setuju (STS) $=0 \times 1=0$

Sehingga total perolehan skor dari semua responden adalah 87.

Jumlah skor maksimal yang bisa dicapai adalah skor tertinggi $\mathrm{x}$ jumlah butir soal $\mathrm{x}$ jumlah responden $=4 \times 5 \times 5=100$

Tabel 2. Skor Presentase

\begin{tabular}{|c|c|}
\hline Presentase & Interpretasi \\
\hline $25(\%)$ & Tidak Baik \\
\hline $26-50(\%)$ & Kurang Baik \\
\hline $51-75(\%)$ & Baik \\
\hline $76-100(100 \%)$ & Sangat Baik \\
\hline
\end{tabular}


Rumus untuk mengetahui presentase hasil pengujian $=$ (Skor yang didapat $/$ Skor maksimal) x 100 sehingga (87 / 100) x $100=87 \%$ hasil presentase mengunakan perhitungan skala likert diperoleh presentas sebesar 87\%, sehingga Sistem Informasi Manajemen Konfeksi Pakaian Di Ady Taylor Berbasis Website ini sangat baik dan layak untuk digunakan.

\section{KESIMPULAN}

Setelah melakukan penelitian serta membahas hasil penelitian secara tuntas sehingga tercipta Sistem Informasi Manajemen Konfeksi Pakaian Di Ady Taylor Berbasis Website, maka dapat di ambil kesimpulan bahwa sistem informasi yang telah dibangun tersebut sangat baik dan layak untuk digunakan serta semua fungsi dapat digunakan. Sistem informasi tersebut dapat merekap laporan dan dapat mengolah data bahan baku dengan baik

\section{SARAN}

Peneliti berharap sistem informasi yang dibangun dapat berguna untuk pengelola konfeksi di ady taylor dalam melakukan proses transaksi dan perekapan laporan secara cepat dan efektif. Adapun beberapa saran dari peneliti untuk bahan pertimbangan bagi pengembangan sistem kedepannya:

1. Perlu adanya penambahan fitur Payment Gateway, sehingga pelanggan bisa melakukan pembayaran secara online.

2. Perlu adanya aplikasi yang berbasis android sehingga pelanggan atau konsumen dapat melakukan pemesanan melalui android.

\section{UCAPAN TERIMA KASIH}

Penulis menyampaikan banyak terimakasih kepada pihak pengelola konfeksi ady taylor yang telah memperkenankan dalam penelitian ini serta semua pihak yang telah memberi dukungan, sehingga penulis dapat membuat jurnal ini.

\section{DAFTAR PUSTAKA}

[1] Suwandi, A., Amperajaya, D., Aura, K., \& Bp, K. 2017, Iptek Bagi Masyarakat (Ibm) Konveksi Pakaian Ciledug pada 2 pengusaha yaitu Konveksi Bapak Situasi Tempat Kerja Terlihat Situasi Kondisi Ruang Kerja Konveksi yang Cukup Agak Padat dan Kurang Pola yang Telah Dipotong Maupun yang Belum. 4(9).

[2] Kaleb, B. J. 2019, Penerapan Sistem Informasi Manajemen dan Pengawasannya di Kantor Pelayanan Pajak Pratama Manado, Jurnal EMBA: Jurnal Riset Ekonomi, Manajemen, Bisnis dan Akuntansi, 7(1), 781-790. https://doi.org/10.35794/emba.v7i1.22555

[3] Wahdah, F., Priyambadha, B., \& Rusdianto, D. S. 2019, Pengembangan Aplikasi Manajemen Perencanaan Bahan Baku dan Pemesanan pada Konveksi Sablon Malang, Jurnal Pengembangan Teknologi Informasi Dan Ilmu Komputer (J-PTIIK) Universitas Brawijaya, 3(1), 538-545. 
[4] Sanwasih, M., \& Sodikin. 2017, Rancang Bangun Aplikasi Pengolahan Bahan Baku Konveksi Abstrak Moch Sanwasih, Sodikin, Rancang Bangun Aplikasi Pengolahan 4(1), $78-88$.

[5] Farhan, M. 2020, Perancangan Sistem Inventori dan Penjualan Pakaian di Konveksi Aulia Collectio, Jurnal Riset dan Aplikasi Mahasiswa Informatika (JRAMI), 1(02), 171176. https://doi.org/10.30998/jrami.v1i02.234

[6] Prasanti, D. 2018, Penggunaan Media Komunikasi Bagi Remaja Perempuan Dalam Pencarian Informasi Kesehatan, LONTAR: Jurnal Ilmu Komunikasi, 6(1), 13-21. https://doi.org/10.30656/lontar.v6i1.645

[7] Tabrani, M. 2018, Penerapan Metode Waterfall pada Sistem Informasi Inventori PT. Pangan Sehat Sejahtera, Jurnal Inkofar, 1(2), 30-40. https://doi.org/10.46846/jurnalinkofar.v1i2.12

[8] Jaya, T. S. 2018, Pengujian Aplikasi Dengan Metode Blackbox Testing Boundary Value Analysis (Studi Kasus: Kantor Digital Politeknik Negeri Lampung). Jurnal Informatika: Jurnal Pengembangan IT (JPIT), 3(2), 45-48.

[9] Taluke, D., Lakat, R. S. M., Sembel, A., Mangrove, E., \& Bahwa, M. 2019, Analisis Preferensi Masyarakat Dalam Pengelolaan Ekosistem Mangrove Di Pesisir Pantai Kecamatan Loloda Kabupaten Halmahera Barat. Spasial, 6(2), 531-540.

[10] Fridayanthie, Eka Wida, \& Mahdiati, T. 2016, Rancang Bangun Sistem Informasi Permintaan ATK Berbasis Intranet, Resma, 3(2), 13-22. 